ESTUDOS RBE?

\title{
Ações afirmativas na Universidade Federal do Maranhão*
}

Regimeire Oliveira Maciel

\section{Resumo}

Objetiva discutir alguns aspectos do processo de implantação de políticas de ação afirmativa, por meio do sistema de cotas para estudantes negros aprovado no ano de 2006, na Universidade Federal do Maranhão (UFMA). Para o desenvolvimento da pesquisa, além de levantamento bibliográfico e coleta de dados quantitativos, foram realizadas entrevistas abertas com dois dos principais sujeitos envolvidos na aprovação do sistema: o Núcleo de Estudos Afro-Brasileiros (Neab) e a Pró-Reitoria de Ensino/UFMA. As noções de racismo, raça e ações afirmativas são centrais nas reflexões aqui apresentadas. Ao final, sinaliza que a adoção de políticas de ação afirmativa requer inúmeras transformações nos ambientes em que se instalam, pois a sua aprovação, por mais "consensual" que seja, não garante a efetivação dos seus objetivos.

Palavras-chave: ação afirmativa; negros; universidade; cotas.

* Este artigo, com algumas modificações, é parte integrante da dissertação de mestrado "Ações afirmativas e universidade: uma discussão do sistema de cotas da UFMA", defendida na Pontifícia Universidade Católica de São Paulo em 2009. 


\section{Abstract \\ Affirmative action program in the Federal University of Maranhão (UFMA)}

The present article aims to discuss some aspects of the process of affirmative action program policies at the Maranhão State Federal University (UFMA), which culminated with the implementation of racial quotas for black students approved in 2006. In the development of the research, besides the bibliographical search and quantitative data collection, were performed open interviews with two of the main players involved in the system's approval: the Afro-Brazilian Studies Centre (NEAB), and the Undergraduate Studies Council/UFMA members. The notion of race, racism and affirmative actions are key concepts in this study. The conclusion seems to be that the implementation of affirmative action programs requires several changes in the environment where they are to be implemented because their approval, however consensual they may be, does not ensure the effectiveness of their intended goals.

Keywords: affirmative action; black people; college; quotas.

Os debates sobre políticas de ação afirmativa são intensificados no contexto brasileiro a partir da década de 1990: por mais que suas bases tenham sido lançadas por muitas ações do movimento negro brasileiro ao longo da sua trajetória, é decisivamente nessa década que se concentra grande parte dos aspectos norteadores da elaboração e da implementação de políticas específicas em beneficio da população negra. ${ }^{1}$

No Brasil, as ações afirmativas podem ser caracterizadas a partir de dois aspectos: o primeiro localiza essas políticas enquanto elemento integrante da pauta de reivindicações das diversas organizações do movimento negro nacional; e o segundo situa tais medidas enquanto mecanismo que potencialmente pode contribuir na transformação das relações étnico-raciais no seio da sociedade brasileira. As ações afirmativas adquirem esse caráter quando garantem a ampliação dos debates sobre as condições nas quais se encontra a população negra e, nesse sentido, propõem-se a combater os efeitos do racismo, elemento fundamental na definição de oportunidades e no acesso a bens e direitos por parte dessa população.

Nessa perspectiva, duas noções são fundamentais: a de racismo e a de ações afirmativas. A primeira abrange todas as dimensões das manifestações racistas na sociedade brasileira, referindo-se principalmente à atuação das instituições na criação, reprodução e manutenção de práticas
1 O deputado federal Abdias Nascimento, em 1983, propôs o projeto de Lei $n^{\circ} 1.332$, que previa uma "ação compensatória" para o afro-brasileiro (Moehlecke, 2002). 
e valores capazes de expor a população negra a graves desigualdades. Segundo Munanga (2000, p. 24), o racismo é

[...] uma crença na existência das raças naturalmente hierarquizadas pela relação intrínseca entre o físico e o moral, o físico e o intelecto, o físico e o cultural. O racista cria a raça no sentido sociológico, ou seja, a raça no imaginário do racista não é exclusivamente um grupo definido pelos traços físicos. A raça na cabeça dele é um grupo social com traços culturais, linguísticos, religiosos, etc. que ele considera naturalmente inferiores ao grupo ao qual ele pertence. De outro modo, o racismo é essa tendência que consiste em considerar que as características intelectuais e morais de um dado grupo são consequências diretas de suas características físicas ou biológicas.

Dessa forma, o racismo não toma negativamente apenas as diferenças, mas principalmente mantém-se como mecanismo de exposição das suas vítimas a desvantagens no mundo social. A noção de ações afirmativas, por sua vez, relaciona-se à explicitação dos efeitos do racismo e dos caminhos necessários à sua alteração. Neste artigo, fizemos opção pela definição de Joaquim Barbosa Gomes (2003, p. 27), que as compreende como

[...] um conjunto de políticas públicas e privadas de caráter compulsório, facultativo ou voluntário, concebidas com vistas ao combate à discriminação racial, de gênero, por deficiência física e de origem nacional, bem como para corrigir ou mitigar os efeitos presentes da discriminação praticada no passado, tendo por objetivo a concretização do ideal de efetiva igualdade de acesso a bens fundamentais como a educação e o emprego.

Quando pensadas para o contexto acadêmico, tais políticas têm suscitado inúmeros debates, e sua modalidade denominada cotas raciais tem questionado discursos e práticas dentro e fora das universidades brasileiras no que tange aos indicadores e às formas de participação da população negra nessas instituições.

Aqui nos propomos a discutir alguns dos aspectos relativos a essa questão a partir da experiência da Universidade Federal do Maranhão (UFMA). A intenção é analisar a disputa entre os sujeitos envolvidos na implementação do programa de ações afirmativas da UFMA, as articulações e concessões necessárias à sua aprovação e os elementos que contribuíram para a configuração atual do sistema de cotas na instituição mencionada. Iniciaremos essa discussão pela exposição de alguns dados relativos à presença de estudantes negros na UFMA, seguida da apresentação do contexto em que surge a proposta para a implantação das ações afirmativas, e chegaremos às repercussões da aprovação e da implantação dessas políticas.

\section{A presença negra na Universidade Federal do Maranhão}

De acordo com o Instituto Brasileiro de Geografia e Estatística (IBGE), em 2007, o Estado do Maranhão tinha uma população estimada 
em 6.118.995 habitantes e possuía uma taxa de analfabetismo de 21,5\% na faixa etária de 15 anos ou mais. Na população considerada branca, nessa mesma faixa etária, essa taxa era de 14,8\%; já para os pretos e pardos os percentuais eram de $27,9 \%$ e $22,7 \%$, respectivamente (IBGE, 2008). No âmbito do ensino superior, havia 71.898 matrículas distribuídas em 28 escolas de nível superior, sendo duas estaduais, uma federal e 25 pertencentes à iniciativa privada. ${ }^{2}$

Ao apresentar tais dados, não temos a intenção de aprofundar as inúmeras questões por eles suscitadas; nosso objetivo é apenas tomá-los com a finalidade de chamar a atenção para a reduzida oferta de ensino superior público e o alto índice de analfabetismo da população negra. Podemos aludir que a elevada taxa de analfabetismo representa, entre outros aspectos, uma acentuada precarização do ensino público sob o ponto de vista da expansão e da melhoria das escolas em todas as regiões do Estado, da própria qualidade do ensino oferecido e da falta de valorização dos profissionais da área. Da mesma forma que as altas taxas de analfabetismo podem estar relacionadas às questões citadas anteriormente, os indicadores sobre a educação superior no Estado pautam a abrangência reduzida da iniciativa pública, retomando também o debate acerca das condições sob as quais as instituições privadas de ensino superior se instalam, permanecem e disponibilizam serviços educacionais. ${ }^{3}$

A UFMA é a maior instituição pública federal de ensino superior do Estado: tem aproximadamente 10.438 estudantes matriculados em 46 cursos de graduação, conta com 375 alunos em 11 cursos de mestrado e um de doutorado e a grande maioria dos cursos está concentrada no campus da capital - São Luís. A questão da interiorização é uma constante nos debates sobre a necessidade de expansão dessa instituição para outras localidades do Estado. A ampliação da sua presença nos diversos municípios é vista pela administração como uma condição essencial para a efetivação dos seus objetivos enquanto instituição financiada por toda a população. No texto do projeto da UFMA de adesão ao Programa de Apoio a Planos de Reestruturação e Expansão das Universidades Federais (Reuni), do Ministério da Educação, a universidade faz alusão à recente política de inclusão sociorracial adotada enquanto mecanismo de expansão: ${ }^{4}$

[...] propomos que os investimentos no sistema público de ensino superior devem prever tanto políticas de ampliação do acesso quanto o fomento da permanência de estudantes em situação de vulnerabilidade. Nosso Programa mostra que as IES, ao implementarem políticas e ações afirmativas consistentes, habilitam-se para enfrentar o secular sistema de desigualdades sócio-raciais, começando a combater sua reprodução já na dimensão do acesso à Universidade, mas ampliando o combate, correspondentemente, a todos os espaços acadêmicos. (UFMA, 2007, p. 39).

A partir dessa referência, podemos considerar que a UFMA reconhece no programa de ações afirmativas, adotado a partir de 2007, a possibilidade de expansão de seus campi e cursos com o intuito de atender aos diversos setores da sociedade maranhense. Entretanto, mesmo diante da

\footnotetext{
${ }^{2}$ Dados do IBGE a partir dos números divulgados pelo Instituto Nacional de Estudos e Pesquisas Educacionais Anísio Teixeira (Inep) no Resumo Técnico do Censo da Educação Superior 2007.

${ }^{3}$ Não pretendemos entrar na questão da qualidade da formação nas universidades privadas, mas é preciso frisar que a lógica que orienta algumas dessas instituições parece desconsiderar a necessidade de formação universitária para além de formação profissional. Esse é um tema que também está presente nas discussões sobre a reestruturação das instituições públicas.

${ }^{4}$ Dados do ano de 2006 encontrados no texto Reuni UFMA (UFMA, 2007). Atualmente, a universidade conta com 13 cursos de mestrado, três de mestrado e doutorado e um de doutorado em rede.
} 
possibilidade de seu crescimento, acreditamos que se tornam necessários alguns questionamentos acerca da forma adquirida pelo programa após sua aprovação. Voltaremos a essa questão na última seção deste artigo, antes, porém, apresentaremos alguns dados relativos à presença negra na UFMA.

No que diz respeito à sua composição racial, essa universidade apresentava em 2002 42,8\% de estudantes negros e 47\% de brancos; a população negra no Estado, na época, estava em torno de 75,1\%. Esses dados são parte de uma pesquisa realizada pelo programa "A Cor da Bahia", da Universidade Federal da Bahia (UFBA), no ano de 2002, e foram recolhidos nas Universidades Federais da Bahia, do Rio de Janeiro, do Maranhão, do Paraná e de Brasília. A análise da distribuição dos estudantes segundo a cor e a universidade (Tabela 1) demonstrou que os brancos representavam em 2002 mais da metade dos estudantes na grande maioria das universidades investigadas, enquanto o segmento populacional negro estava sub-representado, considerando seu percentual no conjunto da população em cada Estado (Queiroz, 2004). ${ }^{5}$

Tabela 1 - Distribuição Percentual de Estudantes segundo a Cor e a Universidade

\begin{tabular}{|l|r|r|r|r|r|}
\hline \multicolumn{1}{|c|}{ Cor } & UFRJ & UFPR & UFMA & \multicolumn{1}{c|}{ UFBA } & \multicolumn{1}{c|}{ UnB } \\
\hline Branca & 76,8 & 86,8 & $\mathbf{4 7 , 0}$ & 50,8 & 63,7 \\
\hline Parda & 17,1 & 7,7 & $\mathbf{3 2 , 4}$ & 34,6 & 29,8 \\
\hline Preta & 3,2 & 0,9 & $\mathbf{1 0 , 4}$ & 8,0 & 2,5 \\
\hline Amarela & 1,6 & 4,1 & $\mathbf{5 , 9}$ & 3,0 & 2,9 \\
\hline Indígena & 1,3 & 0,8 & $\mathbf{4 , 3}$ & 3,6 & 1,1 \\
\hline Total & $\mathbf{1 0 0 , 0}$ & $\mathbf{1 0 0 , 0}$ & $\mathbf{1 0 0 , 0}$ & $\mathbf{1 0 0 , 0}$ & $\mathbf{1 0 0 , 0}$ \\
\hline
\end{tabular}

Fonte: Pesquisa direta (Queiroz, 2004).

Apenas na UFMA os estudantes brancos não constituem a metade do corpo discente, no entanto ultrapassam o seu percentual de representação na população geral do Estado (Tabela 2).

Tabela 2 - Participação dos Brancos no Conjunto da População do Estado e sua Presença na Universidade

${ }^{5}$ Utilizamos os dados do ano de 2002 devido à inexistência de dados mais recentes sobre a presença de estudantes negros na UFMA. A população negra do Maranhão hoje é de $73,4 \%$, segundo o IBGE (2008).

\begin{tabular}{|l|c|l|c|}
\hline \multicolumn{1}{|c|}{ Estado } & 1. População (\%) & Universidade & 2. População (\%) \\
\hline Rio de Janeiro & 61,7 & UFRJ & 76,8 \\
\hline Paraná & 76,2 & UFPR & 86,8 \\
\hline Maranhão & $\mathbf{2 4 , 8}$ & UFMA & $\mathbf{4 7 , 0}$ \\
\hline Bahia & 22,1 & UFBA & 50,0 \\
\hline Distrito Federal & 45,9 & UnB & 63,7 \\
\hline
\end{tabular}

Fonte: IBGE/Pesquisa direta (Queiroz, 2004). 
Tabela 3 - Participação de Negros no Conjunto da População do Estado e sua Presença na Universidade

\begin{tabular}{|l|c|l|c|}
\hline \multicolumn{1}{|c|}{ Estado } & 1. População (\%) & Universidade & 2. População (\%) \\
\hline Rio de Janeiro & 38,2 & UFRJ & 20,3 \\
\hline Paraná & 22,4 & UFPR & 8,6 \\
\hline Maranhão & $\mathbf{7 5 , 1}$ & UFMA & $\mathbf{4 2 , 8}$ \\
\hline Bahia & 77,5 & UFBA & 42,6 \\
\hline Distrito Federal & 53,6 & UnB & 32,3 \\
\hline
\end{tabular}

Fonte: IBGE/Pesquisa direta (Queiroz, 2004).

Observando a Tabela 3, verificamos que é significativa a distância na representatividade dos brancos em relação aos negros no conjunto geral da população em cada Estado e sua participação na instituição de ensino superior. Em síntese, nas universidades pesquisadas, os estudantes negros representam um número bem menor se levarmos em conta a sua participação na população de cada Estado.

Apesar da inexistência de dados quantitativos e qualitativos atualizados que demonstrem os níveis de participação da população negra na UFMA, identificando, por exemplo, em quais áreas de conhecimento ela está mais representada nos últimos anos, é necessário levar em conta que a participação dessa população continua inferior à sua proporção na população do Estado e está concentrada nas áreas consideradas de baixo prestígio social e de mais rápido acesso ao mercado de trabalho. ${ }^{6}$

Os dados anteriormente mencionados serviram para subsidiar a discussão das políticas de ação afirmativa na UFMA, por isso, nesta reflexão, levaremos em consideração suas contribuições para a implantação dessas políticas na referida instituição.

De maneira geral, para a compreensão da dinâmica das ações afirmativas na UFMA, partimos da hipótese de que foi estabelecida uma disputa entre os principais atores envolvidos e que é preciso apreender o grau de "investimento" de cada um na condução dos debates e no encaminhamento final da proposta. Assim, discutiremos, de um lado, a forma e o caráter de algumas ações empreendidas pelo Núcleo de Estudos Afro-Brasileiros (Neab) enquanto proponente das políticas de ação afirmativa e, de outro, os desdobramentos da reação dos vários setores da administração universitária à proposta apresentada. A intenção é, portanto, verificar o resultado dessa disputa na caracterização final do projeto aprovado e implementado.

\section{O contexto das ações afirmativas na UFMA}

Em 2004, a exemplo de outras universidades públicas, iniciou-se na UFMA o processo de discussão para a adoção de medidas que
${ }^{6}$ Esta suposição tem por base o trabalho de Queiroz (2004). 
A Universidade do Estado da Bahia, a Universidade do Estado do Rio de Janeiro e a Universidade do Norte Fluminense foram as primeiras a adotar políticas de ação afirmativa para estudantes negros. contribuíssem, de forma geral, para a alteração de desigualdades raciais no interior da instituição e permitissem, entre outros aspectos, o aumento do percentual de estudantes negros nos seus cursos de graduação. ${ }^{7}$ A elaboração da proposta foi conduzida por pesquisadores que integram o Neab, núcleo formado, em sua maioria, por professores e estudantes dos cursos de graduação e pós-graduação da UFMA e que se caracteriza como um grupo que desenvolve pesquisas acadêmicas voltadas para os estudos das populações afro-brasileiras em suas diversas perspectivas. A dinâmica dos estudos desenvolvidos pelo Neab e o papel político por ele assumido na referida universidade o aproximou dos debates sobre políticas focalizadas para a população negra e contribuiu para a definição dos eixos do programa de ações afirmativas da UFMA.

Os pressupostos para elaboração da proposta do programa de ações afirmativas para a UFMA estão, na nossa avaliação, em dois fatores que sustentam os principais argumentos favoráveis e as justificativas para implantação dessas políticas na sociedade brasileira: o primeiro envolve a noção de compensação, referindo-se aos prejuízos causados à população negra no decorrer da história do País, e o segundo chama a atenção para a necessidade de enfrentar as diversas facetas do racismo cotidianamente experimentado por essa população.

No primeiro, temos as discussões sobre o papel do passado na configuração atual da sociedade brasileira; trata-se da compreensão do período escravocrata enquanto processo que subjugou amplamente a população negra. A escravidão e os demais processos desencadeados por ela seriam, dessa forma, responsáveis pelos danos materiais e simbólicos causados a essa população. Esse aspecto faz referência, sobretudo, à dinâmica adquirida por esse passado nas condições atuais de vida da população brasileira. Todavia, passa a considerar também outros prejuízos causados no presente não necessariamente atrelados ao passado escravocrata.

O segundo fator apresenta-se como um desdobramento do primeiro. A compreensão do racismo tomado como foco para análise das condições de vida da população negra não pode ignorar as repercussões do passado para essa população, entretanto é preciso identificar as condições que permitem ao racismo atuar cotidianamente na definição das trajetórias dos sujeitos negros. Não se trata de uma relação simples de causa e efeito, mas de um fenômeno que tem nos aspectos que definem o pertencimento racial a principal razão para se desenvolver. As políticas de ação afirmativa, nesse caso, tomam como ponto de referência a necessidade de minimizar a atuação do racismo na definição de oportunidades, como no acesso ao ensino superior, por exemplo.

Dessa forma, as discussões que abarcam os dois fatores apresentados localizam as desigualdades e passam a relacioná-las à conotação negativa atribuída aos elementos que referenciam o pertencimento racial. O que justificaria a adoção de ações afirmativas, em diversas instâncias, seria a existência de uma estrutura de poder que produz e alimenta o racismo, provocando desigualdades que não podem ser amenizadas por meio das chamadas políticas universalistas ou de medidas que apenas proíbam a 
discriminação racial. Podemos encontrar parte desse raciocínio em Gomes (2003, p. 29), quando considera que:

Em regra geral, justifica-se a adoção das medidas de ação afirmativa com o argumento de que esse tipo de política social seria apta a atingir uma série de objetivos que restariam normalmente inalcançados caso a estratégia de combate à discriminação se limitasse à adoção, no campo normativo, de regras meramente proibitivas de discriminação.

As ações afirmativas têm sua validade atestada, assim, pela necessidade de desmantelamento ou pelo menos de enfrentamento de uma estrutura que impõe a um importante segmento da sociedade brasileira oportunidades desiguais de todas as ordens. A formalização jurídica da proibição do racismo não impediu a sua manifestação e, principalmente, não impediu a produção de resultados desvantajosos para esse segmento.

Há, ainda, um fator, com alguns desdobramentos, que se soma aos anteriores na caracterização das ações afirmativas na sociedade brasileira: a intensificação da luta antirracista no País (Carvalho, 2003, 2006). Essa intensificação pode ocorrer na medida em que o debate sobre a importância das políticas de ação afirmativa retoma alguns elementos sobre o entendimento do caráter das relações entre negros e brancos no Brasil, recolocando os seus aspectos, na maioria das vezes, a partir de dois questionamentos: a abrangência do racismo e as possibilidades de identificação dos beneficiários dos programas de ação afirmativa.

De forma geral, a frequência com que essas questões têm sido tratadas confirma que o reconhecimento da existência do racismo enquanto fenômeno que estrutura relações ainda é problemático. Nesse debate, dois pontos devem ser considerados: primeiro, questionar a existência do racismo é não admitir que foram designados aos negros os piores lugares na esfera social, como têm apontado, inclusive, diversos indicadores socioeconômicos; depois, alegar dificuldade para identificar os beneficiários das ações afirmativas é ignorar os aspectos nos quais a discriminação racial se inscreve. Porém, esses questionamentos têm dado novo vigor às lutas empreendidas para superação do racismo à medida que as ações afirmativas forçaram a explicitação e o enfrentamento de tais questões.

Essas motivações, argumentações e questionamentos compuseram os debates instaurados internamente no Neab acerca da necessidade de ações afirmativas na UFMA. Além dos aspectos apresentados, que se tornaram referências importantes para esse processo, há ainda marcos específicos para a discussão, a elaboração e a implantação dessas políticas no interior da UFMA, entre eles a discussão das experiências acumuladas por algumas instituições ao implantarem programas de ação afirmativa para estudantes negros e os debates desencadeados pelo III Congresso de Pesquisadores(as) Negros(as) (Copene), realizado em São Luís em 2004.

Em relação ao primeiro aspecto, há pelo menos duas experiências de ações afirmativas em universidades que estimularam o Neab a fomentar os debates na UFMA: as experiências da Universidade do Estado da Bahia (Uneb) e as da Universidade de Brasília (UnB). ${ }^{8}$

\footnotetext{
${ }^{8}$ Os(as) professores(as) José Jorge de Carvalho (UnB), Jocélio Santos (UFBA), Valter Silvério (UFSCar), Andréia Lisboa (Secad-MEC), Ana Lucia Valente (UnB), Wilson Matos (Uneb), entre outros(as), estiveram em atividades organizadas pelo Neab a respeito das políticas de ação afirmativa na UFMA.
} 
A Uneb, juntamente com a Universidade do Estado do Rio de Janeiro e a Universidade do Norte Fluminense, é considerada pioneira na discussão e aprovação de um sistema de reservas de vagas para estudantes negros. Em 18 de julho de 2002, o Conselho Universitário aprovou um percentual mínimo de $40 \%$ das vagas dos cursos de graduação e pós-graduação da Uneb para candidatos afrodescendentes oriundos de escola pública, e o primeiro vestibular com cotas foi realizado no ano de 2003. Mattos (2004, p. 191), tomando como referência esse processo seletivo e na tentativa de discutir os argumentos que questionam a capacidade dos estudantes cotistas para acompanhar as atividades acadêmicas, informa-nos que:

Com exceção do Departamento de Tecnologia e Ciências - Campus III, departamento em que, no cômputo geral, os estudantes que ingressaram através do Sistema de Cotas obtiveram um rendimento médio 0,3 pontos abaixo de 7,0 (sete) - nota mínima exigida individualmente para a aprovação nas disciplinas -, em todos os demais departamentos as médias das notas obtidas pelos estudantes em todos os cursos e respectivas disciplinas posicionaram-se ligeiramente acima da nota mínima.

A realização de um levantamento ratificando que os estudantes cotistas atendem às condições para fazer um curso de nível superior integra um conjunto de indicadores para programas de ação afirmativa em outras instituições, possibilita a avaliação do desenvolvimento dessas políticas na Uneb, além de sinalizar o quanto as cotas podem alterar as distorções no acesso à universidade pública: "[...] o mais importante é a possibilidade de confirmarmos através de dados objetivos que o sistema de cotas tem se demonstrado acertado como um eficaz corretor da desigualdade racial de acesso ao ensino superior" (Mattos, 2004, p. 193).

Na UnB, o processo de discussão acerca da necessidade de políticas especiais para a população negra na universidade foi intenso, contudo a instituição decidiu em 2003, e passou a adotar a partir de 2004, que 20\% das suas vagas seriam destinadas a estudantes negros por meio do Plano de Metas de Integração Social, Étnica e Racial da UnB, definido como

[...] um conjunto de medidas que pretendem gerar na UnB uma composição social, étnica e racial capaz de refletir minimamente a situação do Distrito Federal e a diversidade da sociedade brasileira como um todo. O fundamento supremo do Plano de Metas é o propósito de promover a inclusão social de negros e indígenas por meio do acesso ao ensino superior, em um contexto de Políticas de Ação Afirmativa. (Unb, [2003]).

A UnB foi a primeira universidade federal a adotar políticas desse cunho. O processo de discussão e aprovação das ações afirmativas ganhou repercussão nacional e estimulou o debate para além da esfera acadêmica, chamando a atenção para os índices elevados de desigualdade entre negros e brancos no ensino superior brasileiro. No texto submetido à aprovação do conselho essas questões estão amplamente colocadas, com a argumentação de que 
[...] não é mais possível, em 2002, continuar discutindo a questão da ausência dos negros do ensino superior como se o assunto girasse exclusivamente em torno de qualificação e mérito pessoal. Nós, membros da comunidade acadêmica que nos guiamos pelas evidências da pesquisa empírica, possuímos agora conhecimento objetivo de que os negros estão ausentes da universidade como consequência de um mecanismo estrutural de privilegiar os brancos. E onde há privilégio racial não há universalismo. Diante disso, ou modificamos nossos critérios de acesso para inverter esse mecanismo automático de favorecimento aos brancos ou contribuiremos - agora sem a desculpa do desconhecimento - para a perpetuação da exclusão secular do negro do ensino superior no Brasil. (Carvalho, Segato, 2002, p. 17).

Outro aspecto que marcou a implantação das ações afirmativas na UFMA foi a organização e realização do III Copene. Na fala do professor doutor Carlos Benedito Rodrigues da Silva, coordenador do Neab, observamos a referência ao congresso como importante marco para as discussões das ações afirmativas na UFMA:

[...] aqui, em 2003, nós começamos a discutir a organização do III Congresso de Pesquisadores(as) Negros(as) - Copene. [...] em 2000, começam a acontecer os Congressos de Pesquisadores(as) Negros(as) e aí as propostas. Uma das propostas do Copene era exatamente de ampliar a presença negra, de intelectuais negros nas universidades através de um programa de ação afirmativa, e as discussões giravam não só em torno da graduação, mas também da pós-graduação, dos concursos para professores, etc. Então algumas universidades começam a elaborar programas pra implementação de cotas nas graduações [...]. ${ }^{9}$

Portanto, além da análise das repercussões das ações afirmativas nas primeiras universidades a adotá-las, as discussões que envolveram a organização e a realização dos Congressos de Pesquisadores(as) Negros(as) (Copene) a partir de 2000 impulsionaram os primeiros passos dos debates sobre ações afirmativas na UFMA. Mais precisamente, é a realização do III Copene em São Luís, de 5 a 8 de setembro de 2004, com o tema Pesquisa social e políticas de ação afirmativa para afrodescendentes, que passa a responsabilizar o Neab pelo processo de intensificação das discussões internas sobre tais políticas. A mobilização para a organização do III Copene e as atividades transcorridas durante o evento possibilitaram aos pesquisadores do Neab contato com outros estudiosos das relações étnico-raciais, além do aprofundamento de questões relativas à necessidade e às justificativas das ações afirmativas no contexto brasileiro.

Após o III Copene, o Neab passou a desenvolver ações internas e externas com a finalidade de expor as razões e os objetivos das ações afirmativas na UFMA. Nesse processo, o núcleo realizou seminários, propôs mini-cursos e mesas-redondas nos eventos locais, além de solicitar reuniões setoriais com a finalidade de apresentar à universidade a estrutura geral do programa de ação afirmativa. ${ }^{10}$

Entre essas ações destaca-se o seminário realizado para apresentação da versão final da proposta de ação afirmativa. O evento, intitulado Ações afirmativas para além das cotas: seminário para implantação de

\footnotetext{
${ }^{9}$ Entrevista concedida em 6 de fevereiro de 2009, na sede do Neab/UFMA, em São Luís, Estado do Maranhão.

${ }^{10}$ Além de realizar mesas envolvendo os segmentos docente, discente e administrativo da universidade, o Neab apresentou a proposta em alguns órgãos colegiados dos Centros de Ciências Humanas, Sociais, Exatas e da Saúde.
} 
${ }^{11}$ Professor Carlos Benedito Rodrigues da Silva, entrevista concedida em 6 de fevereiro de 2009.

${ }^{12}$ Nessa fase de mobilização para aprovação de um programa de ação afirmativa para a UFMA, um aspecto se sobressai: a quase ausência das organizações do movimento negro do Estado no referido processo. Apenas a Organização Consciência Negra (Cnegra) participou de forma mais direta das discussões e depois passou a constituir a comissão encarregada do desenvolvimento das etapas necessárias à implementação do programa. um programa de ação afirmativa na UFMA, realizado com o apoio do Departamento de Sociologia e Antropologia dessa instituição, ocorreu de 29 a 31 de agosto de 2006 e teve como objetivo a apresentação do conteúdo geral da proposta já debatida em alguns setores da universidade. Para a exposição das questões relativas ao projeto, foram escolhidos palestrantes representando o Neab, a administração superior e o sindicato de professores da UFMA. O evento também contou com as contribuições do professor Jocélio Santos, da Universidade Federal da Bahia, e da professora Andréia Lisboa, à época representando a Secretaria de Educação Continuada, Alfabetização e Diversidade (Secad), do Ministério da Educação. O seminário teve cerca de 600 participantes e, do ponto de vista da quantidade de ouvintes, foi considerado o maior.

[...] nós organizamos esse seminário, Ações Afirmativas para além das cotas, com a intenção de elaborar um programa que não fosse só as cotas percentuais; que fosse um programa de ação afirmativa com acesso e permanência, com melhorias no sistema de transporte, na alimentação, com bolsas para pesquisa. Enfim, que os estudantes que entrassem pelo sistema de cotas tivessem possibilidade de permanecer na universidade e sair dela com qualificação, com uma formação qualificada. ${ }^{11}$

Paralelamente a esse processo e de forma mais intensa após o seminário do mês de agosto de 2006, o Neab passou a dialogar diretamente com a administração da universidade na preparação para a votação do projeto no Conselho de Ensino, Pesquisa e Extensão (Consepe). É nesse momento que a administração da UFMA apresenta a intenção de incluir no programa de ação afirmativa vagas específicas para indígenas e para pessoas portadoras de necessidades especiais. Essa inclusão ocorreu após alguns ajustes no texto do projeto. ${ }^{12}$

Em geral, a proposição de ações afirmativas na UFMA orientou-se pelo teor do debate em âmbito nacional, que parte do reconhecimento dessas iniciativas como mecanismos de correção de distorções históricas - as referências que marcaram o processo da UFMA sintetizam essa perspectiva. O Neab, ao levantar e defender os principais aspectos que justificaram a formulação do programa de ações afirmativas, precisou lidar, ao mesmo tempo, com a necessidade de contemplar essas motivações mais amplas e com os desafios de escolher estratégias que garantissem a efetivação dos objetivos desse tipo de política, respeitando as especificidades da UFMA e do Estado do Maranhão.

\section{A aprovação das cotas na UFMA}

Após quase três anos de intenso debate nas esferas administrativa e acadêmica, o Neab sistematizou, na segunda metade do ano de 2006, uma proposta de programa de ações afirmativas caracterizada por "[...] um conjunto de ações necessárias ao acesso, permanência e convivência de alunos egressos de escola pública, negros, indígenas e portadores de 
necessidades especiais na Universidade Federal do Maranhão". Nessa perspectiva, os objetivos do programa foram assim estabelecidos:

I - promover as condições institucionais necessárias ao acesso, permanência e convivência dos estudantes de escola pública, negros, indígenas e portadores de necessidades especiais por meio do ingresso pelo sistema de cotas, além de otimizar as condições socioeconômicas e acadêmicas que lhes permitam o aproveitamento integral do espaço universitário. II - fornecer critérios objetivos de avaliação e acompanhamento do Programa instituído e, sobretudo, oferecer condições concretas à construção de cultura universitária democrática e pluralista no Estado do Maranhão. ${ }^{13}$

Em outubro de 2006, a UFMA aprovou, no seu processo seletivo, percentuais específicos para as seguintes categorias: negros, indígenas, portadores de necessidades especiais e oriundos de escola pública. Do total de vagas disponíveis em cada processo, 50\% deveriam ser destinadas à modalidade cotas, sendo $25 \%$ para alunos que se autodeclarem negros, sem considerar a sua origem escolar, e 25\% para os egressos de escolas públicas, independentemente do seu pertencimento racial. ${ }^{14}$ Para os indígenas e para os portadores de necessidades especiais foi reservada uma vaga por curso e por semestre em cada vestibular. Essa foi a configuração do sistema de cotas aprovado unanimemente pelo Consepe em 31 de outubro de 2006. ${ }^{15}$ Entretanto, ao analisar essa etapa do processo de aprovação, o professor Carlos Benedito Rodrigues da Silva considera que,

[...] pelo fato de existir uma predisposição, pelo menos uma sensibilização maior do reitor Fernando Ramos, que defendia o programa, acho que isso mexeu muito com os outros conselheiros; a votação se deu um pouco por conta do Fernando Ramos, acho que por uma leitura equivocada dele de que a gente estava muito apoiado pelo movimento negro [...] Eles tinham a temeridade de que, caso não aprovassem, acontecesse uma reação muito grande do movimento negro contra a universidade. Era uma leitura equivocada, porque a gente não tinha esse apoio, mas foi com o que a gente jogou. Na verdade o movimento negro não estava presente, a gente estava sozinho como continuamos até agora. Enfim, o que estamos vivendo agora é o reflexo daí; o pessoal aprovou talvez por constrangimento, com certeza não por concordar com o programa, especialmente na área da saúde, lá a reação sempre foi maior. [...] o fato de ter sido aprovado a gente considerou um fato muito importante [...] sem duvida foi uma vitória da gente, mas que ficou pela metade porque o programa, a proposta não era cota percentual, os percentuais foram aprovados, mas não era só isso que a gente queria, nós queríamos a aprovação de um programa e nós elaboramos um programa detalhado com ampliação das bibliotecas, de discussão e reformulação curricular, de inclusão da discussão sobre relações raciais nos currículos, nas licenciaturas principalmente, enfim a gente fez uma proposta bastante ampla. Mas a não aprovação [...] refletiu nos encaminhamentos do processo que até hoje está emperrado. Nós já tivemos várias discussões sobre a minuta de resolução e essa resolução não foi reformulada, avaliada [...] A gente já respondeu a várias questões e ela nunca foi submetida à aprovação nos conselhos. ${ }^{16}$

Assim, na etapa de aprovação das cotas na UFMA, um elemento se destaca: a forma, já anunciada desde o momento de discussão, como a

\footnotetext{
${ }^{13}$ Trecho retirado da proposta de minuta que ainda hoje tramita pela universidade.

${ }^{14}$ No texto da proposta do Neab e no edital do primeiro vestibular, o percentual deveria ser destinado aos negros passíveis de sofrerem discriminação racial. A partir do terceiro vestibular, a universidade passou a exigir que os candidatos às vagas da categoria negro tivessem cursado os três anos do ensino médio em escola pública ou tivessem estudado ou fossem estudantes de escola privada com mensalidade de até R\$150,00.

${ }^{15}$ Nessa mesma sessão, a UFMA extinguiu o Processo Seletivo Gradual (PSG) e aprovou três novos cursos, além da ampliação do número de vagas para todos os cursos de graduação oferecidos.

${ }^{16}$ Entrevista concedida em 6 de fevereiro de 2009.
} 
universidade negociou o encaminhamento da proposta. As discussões foram intencionalmente conduzidas pela administração superior para que resultassem na aprovação parcial do projeto original. Com a votação unânime no conselho, aprovou-se somente o acesso, ficando assegurado que, no vestibular seguinte, no ano de 2007, os percentuais ali definidos seriam aplicados de maneira a permitir o acesso dos estudantes mencionados anteriormente. Mesmo considerando que na seção de aprovação do acesso tenha sido criada uma comissão para estudar a aprovação do programa na sua totalidade, a avaliação era de que não se avançou exatamente nas outras ações que, em tese, garantiriam o "sucesso" das ações afirmativas.

Porém, antes de seguir analisando os primeiros rumos da implementação das ações afirmativas na UFMA, gostaríamos de discutir duas questões a partir das informações já explicitadas enquanto marcos e subsídios para a definição do conteúdo da proposta apresentada.

O Copene, como já demonstramos, torna-se um marco importante para o processo acima descrito. Todavia, mesmo reconhecendo a importância dos desdobramentos desse congresso - reunião política e científica composta por pesquisadores de todo o País -, é necessário avaliar que a aprovação das cotas raciais na UFMA, na forma exposta, representou o esforço de um grupo restrito de professores e estudantes em torno de uma questão que deveria interessar à comunidade acadêmica em geral - esse é o primeiro ponto. Nesse sentido, parece interessar às instituições de ensino superior - mesmo com contribuições, numa perspectiva contrária, prestadas por intelectuais negros e brancos ao longo de décadas - um distanciamento dos principais elementos que configuram os conflitos e as demandas relacionadas à formação da sociedade brasileira. Permitir o acesso de um determinado número de estudantes negros às instituições públicas de ensino superior, marcadas pela quase ausência desses e produtoras de um conhecimento científico indiferente aos aspectos sociorraciais responsáveis pela formação do País, significa dar um passo mínimo para a alteração dessas condições.

As políticas de ação afirmativa são atacadas, portanto, principalmente por contestarem uma história que "incentiva" o País a tornar-se indiferente aos seus próprios construtores. De forma mais profunda, é a negação do racismo, dos seus efeitos e dos elementos que o produzem que devemos tomar para analisar a resistência às ações afirmativas e, consequetemente, essa indiferença à necessidade de repensar, de modo específico, a estruturação da universidade no Brasil. As cotas raciais, desse modo, vão contra uma composição acadêmica que legitima a existência apenas de uma versão da história brasileira.

Uma outra questão, enquanto marco para a definição do conteúdo da proposta de ações afirmativas na UFMA, diz respeito à forma adotada na discussão das políticas de ação afirmativa nessa universidade. Seguindo o caminho de outras instituições, esse processo foi orientado principalmente pelas justificativas históricas para a sua implantação. Nesse sentido, observamos que os debates sobre tais medidas quase sempre assumem um 
caráter explicativo. Os expositores tomam a responsabilidade de apresentar os elementos que justificam a necessidade das políticas e de discutir os argumentos favoráveis e contrários à sua implementação. A forma de lidar com essa complexa discussão parece uma resposta antecipada aos vários ataques enfrentados por tais iniciativas. Reconhecemos que, considerando o curto espaço de tempo em que se intensificaram os debates e certo grau de alheamento por parte da grande maioria da população em relação às ações afirmativas no Brasil, torna-se necessária tal dinâmica. Notamos, porém, a partir da experiência da UFMA, que a decisão de discutir política de cotas para estudantes negros, por exemplo, seguindo essa orientação, pode resultar num efeito distinto do esperado pelos seus agentes - há de se considerar a necessidade de discussão minuciosa nesses casos.

Entretanto, a insistência por parte de alguns setores para a compreensão de determinados aspectos da política proposta pode ser tomada como uma tentativa de protelar um processo que pode seguir mais rapidamente. Assim, argumentar contrariamente às políticas de ação afirmativa pode ser um caminho encontrado, inclusive pelas direções das universidades públicas, para adiar o cumprimento de uma responsabilidade historicamente colocada. O que argumentamos é que algumas das dificuldades encontradas nos processos de adoção de cotas no ensino superior têm a ver com esse adiamento intencionalmente construído. A necessidade de discussão das motivações para adoção de políticas de ação afirmativa não deve ser confundida com a intenção de comprovar exaustivamente que a população negra está exposta a um quadro de injustiças e de desigualdades.

Não queremos, no entanto, com essas observações, julgar desnecessárias as várias investidas para a divulgação e discussão das justificativas e dos argumentos relativos às ações afirmativas, mas apenas chamar a atenção para o fato de nos encontrarmos numa fase decisiva para a implantação e o pleno desenvolvimento dessa política, inclusive avaliando seus primeiros impactos. Porém, muitas vezes, empreendemos esforços para responder aos sujeitos interessados apenas no atraso da implantação dessas medidas.

Ainda tomando como referência essa segunda questão, podemos dizer que nos encontramos num momento de intensificação da discussão acerca dos efeitos das ações afirmativas a partir da seguinte pergunta: Quais são as principais transformações do contexto acadêmico, a partir das experiências já implementadas, possibilitadas pela política de cotas para estudantes negros? Mais ainda: Em quais limites essas experiências têm esbarrado do ponto de vista orçamentário, curricular, etc.? Essas são questões fundamentais para pensar a efetivação da ação afirmativa enquanto iniciativa fortemente compromissada com a revisão das bases do saber acadêmico e com a produção de saberes voltados à minimização dos efeitos do racismo existente no País.

Essas indagações, portanto, ilustram os principais desafios a serem enfrentados no atual contexto dos estudos das relações raciais no Brasil e, especificamente, na adoção de ações afirmativas. Para Zoninsein (2006, p. 72-73), 
a maximização dos benefícios líquidos das AA será restringida pela magnitude das preferências dadas aos afrodescendentes (o tamanho das cotas, por exemplo), pela extensão das suas desvantagens socioeconômicas e educacionais, pelo grau de resistência das comunidades acadêmicas, pelo volume do investimento que o governo e a sociedade civil querem e são capazes de mobilizar, assim como pela natureza dos procedimentos institucionais usados para implementar tais políticas.

Nesse sentido, as estratégias utilizadas para discussão e implantação de ações afirmativas devem fazer frente às resistências que se antecipam na forma de argumentações teóricas e políticas e às tentativas de desqualificação pela negação dos meios necessários à efetivação dessas políticas. No contexto acadêmico, por exemplo, a sua adoção deve ser encarada como um mecanismo que possibilite a alteração desse ambiente, pois parece não fazer sentido implantar ações afirmativas nas universidades e manter estruturas financeiras, curriculares, etc., incompatíveis com os seus objetivos e as demandas.

\section{A implantação das cotas na UFMA}

O conteúdo do sistema de cotas adotado pela UFMA, de forma geral, ficou restrito às alterações no vestibular. Os percentuais de $25 \%$ para negros, outros $25 \%$ para oriundos de escola pública e as vagas por curso e por semestre para indígenas e portadores de necessidades especiais são resultados da disputa entre os proponentes e a administração da universidade. O então reitor, declarando-se favorável à adoção das ações afirmativas, assumiu o papel de conciliador entre os interesses do Neab e as resistências dos demais membros da administração superior - o resultado dessa disputa atendeu, em certo sentido, aos dois lados. A incorporação das cotas para negros no vestibular simbolizou para os defensores das ações afirmativas um avanço no processo de democratização da UFMA; por outro lado, a não aprovação do programa de ação afirmativa proposto representou para a universidade, na nossa avaliação, a possibilidade de redirecionamento dos principais eixos do projeto a partir dos seus interesses.

Assim, para o Neab, o vestibular com cotas passou a simbolizar, em parte, um dos aspectos da chamada expansão do ensino superior: o aumento do percentual de estudantes social, étnico e racialmente desfavorecidos em uma universidade pública. Outra leitura aceitável é a de que a atuação da administração da UFMA nesse processo resultou na "concessão" apenas de parte do que era indispensável; o possível parece ter sido obtido por constrangimento, apenas com o objetivo de inserir a universidade no contexto da chamada inclusão sociorracial. Entretanto, em entrevista, o pró-reitor de ensino, professor Aldir Araújo Carvalho Filho, respondendo sobre os significados das cotas na UFMA, assegura que essas iniciativas 
significam identificar e proclamar publicamente que a universidade valoriza a diversidade. Ela reconhece as injustiças sociais e se empenha em alterar esse estado de coisas. Resgata as dividas históricas da sociedade brasileira com os desfavorecimentos, seja por razões de etnia, de cor de pele, seja por origem étnica, no caso indígena, seja desfavorecimento por deficiência física ou de qualquer outra natureza, e, principalmente o desfavorecimento econômico. Então a universidade federal proclama republicanamente o direito universal à educação e que, portanto, todos têm que ter igualdade de oportunidades no acesso. Então políticas de cotas na universidade são fundamentalmente uma afirmação inequívoca nessa crença no direito à igualdade de oportunidade de acesso à educação, não só no ingresso, mas também na permanência. ${ }^{17}$

Com essa referência, queremos destacar a forma como o pró-reitor de ensino, representante da UFMA, trata a questão das ações afirmativas e os aspectos que contribuíram para sua aprovação parcial. No trecho anterior da entrevista parece não existir dúvida quanto à necessidade de medidas específicas para determinados segmentos da sociedade brasileira. Porém, observada a trajetória das ações afirmativas na UFMA, concluímos que não se efetivaram as impressões a respeito dessas iniciativas enquanto políticas que podem nivelar oportunidades.

À luz desses aspectos, passemos à apresentação das características do sistema de cotas aprovado pela UFMA. Da seção de aprovação saiu uma comissão formada por representantes do Neab, da Pró-Reitoria de Ensino (Proen), da Organização Consciência Negra (Cnegra), da Associação de Professores da UFMA (Apruma), do Diretório Central dos Estudantes (DCE) e do Conselho de Ensino, Pesquisa e Extensão (Consepe) para elaborar uma proposta de resolução a partir daquela apresentada pelo Neab. Essa comissão foi oficialmente instituída pela reitoria da universidade, e das discussões travadas resultou uma minuta que, por diversas razões, ainda não foi posta em votação. ${ }^{18}$

Na ausência de uma norma permanente - como consta na proposta de minuta não aprovada - que oriente a etapa do ingresso, a cada ano a universidade tem acrescentado ou retirado elementos quase sempre sem qualquer discussão prévia com os segmentos interessados no acompanhamento do sistema. ${ }^{19}$

De maneira geral, os vestibulares têm ocorrido com as seguintes orientações: no ato da inscrição, o candidato indica em qual categoria deseja concorrer; caso indique que deseja concorrer a vagas destinadas aos estudantes negros, deve declarar-se enquanto tal e apresentar fotografia, além de concordar em participar de uma entrevista com a Comissão Especial de Validação de Opção, a fim de efetivar a sua inscrição. Essa comissão é, no que diz respeito à avaliação dos candidatos negros, geralmente composta por representantes do Neab, do movimento negro e do Núcleo de Eventos e Concursos (NEC), órgão responsável pela execução do vestibular, averiguação da documentação enviada pelo candidato e sua convocação para entrevista, que tem por objetivo expor aos candidatos convocados o caráter das ações afirmativas na UFMA, bem como suas motivações e objetivos.
${ }^{17}$ Entrevista concedida em 4 de fevereiro de 2009. No período de aprovação do sistema de cotas, o professor Aldir ainda não era o pró-reitor de ensino da UFMA.

${ }^{18}$ A mudança na administração da UFMA, associada ao fato da aprovação parcial do projeto inicial, parece ter comprometido o processo de aprovação da minuta.

${ }^{19}$ No primeiro vestibular, por exemplo, a universidade se sentiu autorizada a exigir dos candidatos negros uma suposta declaração escrita que comprovasse a experiência de discriminação racial. Tendo nos anos seguintes rendido inúmeros problemas, essa declaração, sob a pressão do Neab, deixou de ser uma exigência. Na descrição da forma como ocorre o acesso, nos deteremos aos aspectos que envolvem o acesso dos estudantes que se declaram negros. 
Nesse contexto reside a argumentação de que as ações afirmativas, no caso da UFMA, são políticas voltadas para as vítimas da discriminação racial. A entrevista, dessa forma, não cumpre a função de examinar se o candidato é negro ou não, mas de assegurar que os estudantes negros vítimas da discriminação racial sejam os beneficiários das cotas no vestibular. O papel da comissão, portanto, é o de tentar conciliar auto e heteroclassificação, levando em conta, por exemplo, os elementos a partir dos quais a discriminação racial se manifesta. ${ }^{20}$

Com a finalidade de discutir alguns elementos relativos ao perfil dos estudantes negros ingressantes pelo sistema de cotas, tomaremos alguns dados do vestibular do ano de 2008. ${ }^{21}$ A intenção não é avaliar as repercussões provocadas pelo vestibular com um percentual destinado a estudantes negros, mas apenas indagar alguns itens que orientaram as reivindicações por cotas na universidade em questão.

No processo seletivo dos alunos ingressantes em 2008, conforme a Tabela 4, de um total de 13.208 candidatos para todas as categorias, 3.041 se inscreveram para concorrer às vagas destinadas aos estudantes negros nesse mesmo ano. No entanto, apenas 1.995 tiveram suas inscrições efetivadas, de acordo com as exigências do edital que orientou o processo, e 444 foram aprovados para um total de 313 vagas disponíveis em todos os campi da universidade. ${ }^{22}$

Tabela 4 - Origem Escolar dos Estudantes Cotistas Negros

\begin{tabular}{c|c|c|c|r|r|}
$\begin{array}{c}\text { Candidatos } \\
\text { inscritos }\end{array}$ & $\begin{array}{c}\text { Candidatos } \\
\text { efetivados }\end{array}$ & $\begin{array}{c}\text { Candidatos } \\
\text { aprovados }\end{array}$ & \multicolumn{3}{|c|}{ Origem Escolar } \\
\hline \multirow{2}{*}{3.041} & 1.995 & 444 & Pública & 1.118 & 238 \\
\hline
\end{tabular}

${ }^{20}$ Com a adesão da UFMA ao Exame Nacional do Ensino Médio (Enem), em 2009, esse processo passou por alterações.

${ }^{21}$ Fizemos opção por esse processo considerando uma significativa sobra de vagas no primeiro vestibular por conta, entre outros aspectos, da divulgação incipiente do novo formato do vestibular

22 Dados disponibilizados pelo Núcleo de Eventos e Concursos (NEC) após solicitação. Há uma divergência nos dados: o total de aprovados para o percentual destinado aos estudantes negros (444) não coincide com o total de aprovados considerando a discriminação por renda e origem escolar. Segundo o NEC, "esses números foram tirados do questionário socioeconômico e consistem em uma aproximação, pois nem todos os registros dos candidatos inscritos foram armazenados com sucesso no processo de inscrição".

Fonte: Universidade Federal do Maranhão - Núcleo de Eventos e Concursos - 2009

No que diz respeito à origem escolar, há uma ligeira maioria de inscritos e aprovados provenientes da escola pública. Entre os aprovados, cerca de 54,46\% são oriundos de escola pública, e, na verificação de sua renda familiar, observamos que 53,09\% possuem renda na faixa de 1 a 3 salários mínimos (Tabela 5).

Tabela 5 - Renda Familiar dos Estudantes Cotistas Negros

\begin{tabular}{|l|r|c|}
\multicolumn{1}{|c|}{ Renda } & \\
\hline \multicolumn{1}{|c|}{ Faixa (salários mínimos) } & Inscritos & Aprovados \\
\hline De 1 a 3 & 1.140 & 232 \\
\hline De 3 a 5 & 465 & 118 \\
\hline De 5 a 10 & 256 & 62 \\
\hline De 10 a 20 & 74 & 19 \\
\hline Acima de 20 & 31 & 06 \\
\hline
\end{tabular}

Fonte: Universidade Federal do Maranhão - Núcleo de Eventos e Concursos - 2009 
A partir dos dados apresentados, levantamos algumas questões. Em primeiro lugar, o número de inscritos pode ser considerado baixo se verificarmos o percentual da população negra no Estado e o número de matriculados do ensino médio no Maranhão no período analisado - 327.197 matrículas (IBGE, 2008). Temos, aparentemente, uma ampla demanda e uma procura pouco expressiva. Sobre este aspecto, podemos elaborar duas considerações: a dificuldade de alguns potenciais candidatos em identificar-se ao sistema enquanto negros e a falta de divulgação e esclarecimento acerca da existência e do funcionamento do sistema de cotas.

Ao tomar as duas tabelas e observar que mais da metade dos aprovados são oriundos de escola pública e estão na faixa de renda de 1 a 3 salários mínimos, supomos, mesmo desconhecendo os dados dos outros processos, que o sistema de cotas para negros está absorvendo, entre os estudantes negros, aqueles que se encontram na zona considerada mais precarizada do ponto de vista das oportunidades educacionais e do acesso à renda. ${ }^{23}$

De forma geral, a implantação de um recorte étnico-racial no vestibular da UFMA na forma apresentada retoma um importante tema: a dificuldade de institucionalização da questão racial por parte da sociedade brasileira. Alguns dados apresentados na Tabela 5 revelam elementos dessa questão (o número de inscritos, por exemplo), mais nitidamente colocada nas estratégias utilizadas no processo de discussão e negociação para aprovação do sistema, que, na nossa compreensão, contribuiu para a sua atual configuração. A não aprovação do programa de ações afirmativas em sua totalidade caracteriza o principal aspecto dessa resistência à institucionalização da questão racial, traduzida na ausência de projetos relacionados à permanência dos estudantes cotistas.

O processo de institucionalização a que nos referimos se relaciona, inicialmente, ao reconhecimento da presença negra no Brasil com todas as suas contribuições e, principalmente, ao reconhecimento da exposição da população negra ao racismo e às suas consequências. Nesse sentido, no contexto acadêmico, essa questão deve significar mais do que o estabelecimento de um recorte racial nos processos seletivos. A instituição universitária deve passar por uma imprescindível discussão acerca das formas que a constituíram e a sustentam; é necessário, sobretudo, pensar que princípios constituem a sua base, que prerrogativas têm acumulado, sob quais referenciais atua e produz conhecimento e para quais segmentos está voltada. As ações afirmativas devem estimular esse processo enquanto elemento indispensável à concretização dos seus objetivos. Dito isso, a adoção de ações afirmativas nesse ambiente não pode efetivamente acontecer sem:

- [...] Garantir a permanência física dos(as) alunos(as) ingressos(as) através do sistema de cotas.

- Institucionalizar a autonomia orçamentária do programa, isto é, garantir a destinação específica de recursos para o programa, dentro do quadro orçamentário da Universidade Federal do Maranhão [...]

- Promover a reformulação dos currículos incluindo elementos que façam referências à historia da África e das contribuições

\footnotetext{
${ }^{23}$ Essa questão refere-se, de forma especifica, a uma inquietação da fase de discussão do sistema: argumentava-se que, se definidos percentuais específicos para negros sem recorte de renda, entrariam na universidade os estudantes negros provenientes de escola privada e com renda mais elevada.
} 
dos negros para a formação social brasileira, de acordo com a Lei $\mathrm{n}^{\mathrm{o}} 10.639 / 03[\ldots]^{24}$

O não cumprimento de exigências mínimas para a implantação de ações afirmativas nas instituições universitárias implica ter um número significativo de estudantes negros e pobres sem condições de nelas permanecerem por meio de seus próprios recursos. Aqui o foco do debate deve ser quanto cada universidade está disposta a investir, em todos os aspectos, para garantir a sustentabilidade dos programas de ação afirmativa. Segundo Zoninsein (2006, p. 64), os "patrocinadores e promotores" de políticas desse tipo

[...] conceberam equivocadamente as AA [ações afirmativas] como um mero processo burocrático de realocação dos recursos disponíveis, em que os resultados das oportunidades educacionais e as realizações acadêmicas são supostamente automáticos e os custos dos investimentos são insignificantes; [...] esses agentes não analisaram a gestão das instituições nem propuseram mecanismos institucionais específicos para maximizar os benefícios líquidos potenciais das AA para seus beneficiários e para a sociedade brasileira como um todo.

Em síntese, o debate central instaurado nos processos de adoção de ações afirmativas no ensino superior deve assentar-se em seu potencial transformador. Essas iniciativas isoladas não podem responder a um conjunto de desigualdades historicamente estruturadas em função do racismo, mas passam a enfrentá-lo quando produzem ou estimulam a criação de mecanismos que deem conta desse desafio. Por conta dessa prerrogativa, as cotas, como modalidade de ação afirmativa, devem não só integrar um esforço para permitir a ampliação do percentual de estudantes negros nas universidades públicas, mas também possibilitar uma formação adequada a esses estudantes. Essa discussão parte do princípio de que essas instituições já não possuem mecanismos voltados a esse fim, e, com as cotas, a demanda por essas condições aumentará. Assim, ao tomarem a decisão de incluir quantitativamente estudantes discriminados social e racialmente, as universidades passam também a incluir novas demandas por assistência acadêmica, financeira, etc., que reclamam mais que reorientações orçamentárias e exigem redefinição de prioridades.

No caso da UFMA, como adiantamos, os desafios se ampliam pela inexistência de novas iniciativas de apoio aos estudantes que ingressaram pelo sistema de cotas nos três vestibulares já realizados. Questionado sobre os primeiros impactos das cotas na UFMA, o professor Aldir Araújo Carvalho Filho afirma que:

Do ponto de vista do custo para realização dessa política, para o ingresso ela não altera fundamentalmente muita coisa; o custo, um custo maior exige, por exemplo, a questão da acessibilidade, não é? Na medida em que nós, a instituição, não nos encontramos ainda razoavelmente estruturados para atender com qualidade a acessibilidade, a necessidade da acessibilidade. Mas tudo isso ta sendo equacionado, [...] mas causa um impacto, causa um impacto também do ponto de vista da assistência
${ }^{24}$ Trecho retirado da proposta de minuta apresentada à universidade. 
estudantil, mas para isso a universidade tem recebido algum apoio do governo federal, dos órgãos de fomento, no sentido de fornecimento de alimentação através do restaurante universitário, de outras ações de assistência especifica $[\ldots] .^{25}$

O apoio do governo federal, mencionado pelo pró-reitor de ensino, materializa-se na disponibilização de verbas para o Plano Nacional de Assistência Estudantil nas universidades federais. Na UFMA, por exemplo, os recursos são direcionados para ações como alimentação, moradia, programas de estágio, etc., conforme a Tabela 6, relativa ao ano de 2008.

Tabela 6 - Programas e Projetos Realizados pelo Núcleo de Assuntos Estudantis (NAE) - 2008

\begin{tabular}{|c|c|c|}
\hline Programas/Projetos & & Atendidos/mês \\
\hline Programa de Residência Universitária & 80 & estudantes \\
\hline Programa Bolsa Alimentação & 528 & estudantes (em média) \\
\hline $\begin{array}{l}\text { Programa de Encaminhamento Médico/ } \\
\text { Odontológico }\end{array}$ & 116 & encaminhamentos \\
\hline Programa de Apoio Psicológico & 306 & atendimentos \\
\hline $\begin{array}{l}\text { Projeto Psicopedagógico "Oficinas de } \\
\text { Motivação" }\end{array}$ & 94 & estudantes atendidos \\
\hline Programa Bolsa Trabalho & 204 & estudantes (em média) \\
\hline $\begin{array}{l}\text { Programa de Bolsa de Língua } \\
\text { Estrangeira do NCL }\end{array}$ & 44 & estudantes \\
\hline $\begin{array}{l}\text { Projeto INCLUIR de Acesso a Língua } \\
\text { Estrangeira }\end{array}$ & 1.800 & estudantes \\
\hline Programa de Bolsas, Recurso Reuni & 46 & estudantes (em média) \\
\hline $\begin{array}{l}\text { Programa de Apoio e Assessoramento } \\
\text { a Eventos Estudantis de Caráter } \\
\text { Acadêmico-Científicos e ao Movimento } \\
\text { Estudantil }\end{array}$ & 260 & estudantes \\
\hline Programa de Estágio Não Obrigatório & 450 & estudantes (em média) \\
\hline
\end{tabular}

Fonte: Núcleo de Assuntos Estudantis (NAE), 2009

Mesmo reconhecendo a importância e a abrangência das ações desenvolvidas e catalogadas pelo NAE, consideramos que não é possível observar uma relação entre os serviços oferecidos e a procura por parte dos discentes. Sabemos quantos estudantes foram atendidos nos programas encaminhados pelo núcleo no ano de 2008, por exemplo, mas não visualizamos quantos efetivamente precisaram desse tipo de apoio.

A partir dessas considerações, podemos inferir que a UFMA aprovou, mas não institucionalizou os aspectos que integram as ações afirmativas na sua dimensão política, isto é, a possibilidade de alteração do contexto acadêmico a partir da inclusão de novos sujeitos e, principalmente, a necessidade de recursos financeiros para assegurar tais alterações.

Dessa forma, a resistência em aprovar os projetos complementares ao sistema de cotas, a ausência de avaliações sobre os vestibulares já
${ }^{25}$ Entrevista concedida em 4 de fevereiro de 2009. 
realizados e a "invisibilidade" imposta aos cotistas por meio da inexistência de um sistema de acompanhamento que aponte os aspectos da sua trajetória acadêmica revelam as dificuldades da UFMA para sustentar e ampliar as políticas de ação afirmativa internamente aprovadas, mas ainda voltadas exclusivamente para a ampliação quantitativa do acesso dos grupos beneficiários do sistema de cotas.

Os desafios estão, portanto, para além da urgência na adoção de medidas que garantam a sustentabilidade das ações afirmativas nas universidades, também na necessidade de construção de referenciais que permitam a análise da atuação de tais políticas por meio da avaliação dos principais impactos para os seus beneficiários e para as instituições nas quais têm sido implantadas.

\section{Referências bibliográficas}

BERNARDINO, Joaze. Levando a raça a serio: ação afirmativa e correto reconhecimento. In: BERNARDINO, Joaze; GALDINO, Daniela (Orgs.). Levando a raça a sério: ação afirmativa e universidade. Rio de Janeiro: DP\&A, 2004.

BRASIL. Instituto Nacional de Estudos e Pesquisas Educacionais Anísio Teixeira (Inep). Notícias. Disponível em: <www.inep.gov.br/imprensa/ noticias/outras/news09_08.htm>. Acesso em: 4 jun. 2009.

. Notícias: Censo da Educação Superior. Disponível em: <www. inep.gov.br/imprensa/noticias/censo/superior/news09_01.htm>. Acesso em: 4 jun. 2009.

BRASIL. Lei no 11.096, de 13 de janeiro de 2005. Institui o Programa Universidade para Todos - PROUNI, regula a atuação de entidades beneficentes de assistência social no ensino superior; altera a Lei no 10.891, de 9 de julho de 2004, e dá outras providências. Diário Oficial da União, 14 jan. 2005. Disponível em: <www.planalto.gov.br/ccivil_03/ Ato2004-2006/2005/Lei/L11096.htm>. Acesso em: 4 jun. 2009

CARVALHO, José Jorge de. Ações afirmativas para negros e índios no ensino superior: as propostas dos NEABs. In: SANTOS, R. E. dos; LOBATO, F. (Orgs.). Ações afirmativas: políticas públicas contra as desigualdades raciais. Rio de Janeiro: DP\&A, 2003.

Inclusão étnica e racial no Brasil: questão das cotas no ensino superior. 2. ed. São Paulo: Altar Editorial, 2006.

CARVALHO, José Jorge de; SEGATO, Rita Laura. Uma proposta de cotas para estudantes negros na Universidade de Brasília. Brasília: 
Universidade de Brasília, Departamento de Antropologia, 2002. (Série Antropologia, n. 314).

CHAUÍ, Marilena de Souza. Escritos sobre a universidade. São Paulo: Ed. Unesp, 2001.

DÁVILA, Jerry. Diploma de brancura: política social e racial no Brasil 1917-1945. São Paulo: Ed. Unesp, 2006. 400p.

FERNANDES, Florestan. Universidade e desenvolvimento. In: IANNI, Otávio. Florestan Fernandes: sociologia militante. São Paulo: Expressão Popular, 2004.

. O negro no mundo dos brancos. 2. ed. rev. São Paulo: Global, 2007.

FERREIRA, Renato. O mapa das ações afirmativas na

educação superior. Disponível em: <www.ibase.br/modules.

php?name=Conteudo\&pid=2252>. Acesso em: 04 jun. 2009.

FREYRE, Gilberto. Casa-grande \& senzala: formação da família brasileira sob o regime da economia patriarcal. 48. ed. São Paulo:

Global, 2003.

FRY, Peter. A persistência da raça. Rio de Janeiro: Civilização Brasileira, 2005.

FRY, Peter; MAGGIE, Yvonne. O debate que não houve: a reserva de vagas para negros nas universidades brasileiras. Enfoques: Revista Eletrônica, Rio de Janeiro, v.1, n.1, 2002.

GASKELL, George. Entrevistas individuais e grupais. In: BAUER, Martin W.; GASKELL, George. Pesquisa qualitativa com texto, imagem e som: um manual prático. 2. ed. Petrópolis: Vozes, 2003.

GOMES, Joaquim Barbosa. A recepção do instituto da ação afirmativa pelo direito constitucional brasileiro. In: SANTOS, Sales Augusto dos (Org.). Ações afirmativas e combate ao racismo nas Américas. Brasília: Ministério da Educação, Secretaria de Educação Continuada, Alfabetização e Diversidade, 2005. p. 45-79.

. O debate constitucional sobre as ações afirmativas. In: SANTOS, Renato Emerson dos; LOBATO, Fátima (Org.). Ações afirmativas: políticas públicas contra as desigualdades raciais. Rio de Janeiro: DP\&A, 2003.

GOMES, Nilma Lino. Cotas para a população negra e a democratização da universidade pública. In: PEIXOTO, Maria do Carmo Lacerda 
(Org.). Universidade e democracia: experiências e alternativas para a ampliação do acesso à universidade pública brasileira. Belo Horizonte: Ed. UFMG, 2004.

GUIMARÃES, Antonio Sérgio Alfredo. Racismo e anti-racismo no Brasil. São Paulo: Fundação de Apoio à Universidade de São Paulo; Editora 34, 1999.

Preconceito e discriminação. São Paulo: Fundação de Apoio à Universidade de São Paulo; Ed. 2004.

HASENBALG, Carlos. Discriminação e desigualdades raciais no Brasil. Traduzido por Patrick Burglin. 2. ed. Belo Horizonte: Editora UFMG; Rio de Janeiro: Iuperj, 2005.

INSTITUTO BRASILEIRO DE GEOGRAFIA E ESTATÍSTICA (IBGE). Síntese de Indicadores Sociais. 2008. Disponível em: http://www.ibge. gov.br/home/estatistica/populacao/condicaodevida/indicadoresminimos/ sinteseindicsociais2008/default.shtm. Acesso em: 02 out. 2009.

Estados: tema educação. 2008. Disponível em: <www.ibge. gov.br/estadosat/temas.php?sigla $=$ ma\&tema $=$ educacao2008 $>$. Acesso em: 28 set. 2009

MACIEL, Regimeire Oliveira. Ações afirmativas e universidade: uma discussão do sistema de cotas da UFMA. 2009. 138f. Dissertação (Mestrado em Ciências Sociais) - Pontifícia Universidade Católica de São Paulo, São Paulo, 2009.

MATTOS, Wilson Roberto de. Inclusão social e igualdade racial no ensino superior baiano: uma experiência de ação afirmativa na Universidade do Estado da Bahia (Uneb). In: BERNARDINO, Joaze; GALDINO, Daniela (Orgs.). Levando a raça a sério: ação afirmativa e universidade. Rio de Janeiro: DP\&A, 2004. p. 189-216.

MOEHLECKE, Sabrina. Ação afirmativa: história e debates no Brasil. Cadernos de Pesquisa, São Paulo, n. 117, p. 197-217, nov. 2002.

MOURA, Clóvis. Sociologia do negro brasileiro. São Paulo. Ática, 1988.

MUNANGA, Kabengele. Uma abordagem conceitual das noções de raça, racismo, identidade e etnia. In: BRANDÃO, A. A. P. (Org.). Programa de educação sobre o negro na sociedade brasileira. Niterói: EdUFF, 2000.

. O anti-racismo no Brasil. In: MUNANGA, Kabengele (Org.). Estratégias e políticas de combate à discriminação racial. São Paulo: Edusp: Estação Ciência, 1996. p. 79-94. 
MUNANGA, Kabengele. Políticas de ação afirmativa em beneficio da população negra no Brasil: um ponto de vista em defesa das cotas. In: GOMES, N. L.; MARTINS, A. A. (Orgs.). Afirmando direitos: acesso e permanência de jovens negros na universidade. Belo Horizonte: Autêntica, 2004.

MUNANGA, Kabengele; GOMES, Nilma Lino. O negro no Brasil hoje. São Paulo: Global, 2006. (Coleção para entender).

NÚCLEO DE ESTUDOS AFRO-BRASILEIROS (Neab). Programa de ações afirmativas para a UFMA. 2006.

PAIXÃO, Marcelo; CARVANO, Luis Marcelo (Orgs.). Relatório anual das desigualdades raciais no Brasil; 2007-2008. Rio de Janeiro: Garamond, 2008. Disponível em: <www.laeser.ie.ufrj.br/relatorios_gerais.asp>. Acesso em: 04 jun. 2009.

PETRUCCELLI. José Luis. A cor denominada: estudos sobre a classificação étnico-racial. Rio de Janeiro: DP\&A, 2007.

QUEIROZ, Delcele Mascarenhas. O negro, seu acesso ao ensino superior e as ações afirmativas no Brasil. In: BERNADINO, Joaze; GALDINO, Daniela (Orgs.). Levando a raça a sério: ação afirmativa e universidade. Rio de Janeiro: DP\&A, 2004. p.137-156.

. Universidade e desigualdade: brancos e negros no ensino superior. Brasília: Líber Livro, 2004.

RAMPINELLI, José; ALVIM, Valdir; RODRIGUES, Gilmar (Orgs.). Universidade: a democracia ameaçada. São Paulo:

Xamã, 2005.

RIBEIRO, Darcy. A universidade necessária. Rio de Janeiro: Paz e Terra, 1969.

SANTOS, Gislene Aparecida dos. A invenção do ser negro: um percurso das ideias que naturalizaram a inferioridade dos negros. São Paulo: Educ, Fapesp; Rio de Janeiro: Pallas, 2002.

SANTOS, Renato Emerson dos. Política de cotas raciais nas universidades brasileiras: o caso da Uerj. In: FERES JÚNIOR, João; ZONINSEIN, Jonas (Orgs.). Ação afirmativa e universidade: experiências nacionais comparadas. Brasília: Editora da Universidade de Brasília, 2006.

SILVA, Petronilha Beatriz Gonçalves. Negros na universidade e produção do conhecimento. In: SILVA, Petronilha Beatriz Gonçalves; 
SILVÉRIO, Valter Roberto (Orgs.). Educação e ações afirmativas: entre a injustiça simbólica e a injustiça econômica. Brasília: Inep, 2003.

SILVEIRA, Oliveira. Vinte de novembro: história e conteúdo. In: SILVA, Petronilha Beatriz Gonçalves; SILVERIO, Valter Roberto (Orgs.). Educação e ações afirmativas: entre a injustiça simbólica e injustiça econômica. Brasília: Instituto Nacional de Estudos e Pesquisas Educacionais Anísio Teixeira (Inep), 2003.

SILVÉRIO, Valter Roberto. O papel das ações afirmativas em contextos racializados: algumas anotações sobre o debate brasileiro. In: SILVA, Petronilha Beatriz Gonçalves; SILVERIO, Valter Roberto (Orgs.). Educação e ações afirmativas: entre a injustiça simbólica e injustiça econômica. Brasília: Instituto Nacional de Estudos e Pesquisas Educacionais Anísio Teixeira (Inep), 2003. p. 55-77.

Ação afirmativa: percepções da "casa grande" e da "senzala". In: BARBOSA, Lúcia Maria de Assunção et al. (Orgs.). De preto a afro-descendente: trajetos de pesquisa sobre o negro, cultura negra e relações étnico-raciais no Brasil. São Carlos: EdUFSCar, 2003. p. 321-341.

SINDICATO NACIONAL DOS DOCENTES DAS INSTITUIÇÕES DE ENSINO SUPERIOR (ANDES-SN). Proposta do Andes-SN para a universidade brasileira. 3. ed., Brasília, 2003. (Cadernos Andes-SN, n. 2).

SISS, Ahyas. Afro-brasileiros, cotas e ação afirmativa: razões históricas. Rio de Janeiro: Quartet; Niterói: Penesb, 2003.

TEIXEIRA, Moema de Poli. Negros na universidade: identidades e trajetórias de ascensão social no Rio de Janeiro. Rio de Janeiro: Pallas, 2003.

TEIXEIRA, Anísio Spínola. Ensino superior no Brasil: análise e interpretação de sua evolução até 1969. Rio de Janeiro: Editora UFRJ, 2005. (Col. Anísio Teixeira, v.10).

UNIVERSIDADE DE BRASÍLIA (UnB). Plano de metas de integração social, étnica e racial da UnB. [2003]. Disponível em: <www.unb.br/ admissao/sistema_cotas >. Acesso em: 23 set. 2009.

UNIVERSIDADE FEDERAL DO MARANHÃO (UFMA). Reuni UFMA. 2007. Disponível em: <www.proen.ufma.br/sigs/admin/fotos/410/ reuniUfma.pdf>. Acesso em: 28 set. 2009.

ZONINSEIN, Jonas. Minorias étnicas e a economia política do desenvolvimento: um novo papel para universidades públicas como 
gerenciadoras da ação afirmativa no Brasil? In: FERES JÚNIOR,

João; ZONINSEIN, Jonas (Orgs.). Ação afirmativa e universidade:

experiências nacionais comparadas. Brasília: Editora Universidade de

Brasília (UnB), 2006.

Regimeire Oliveira Maciel é doutoranda em Ciências Sociais pela Pontifícia Universidade Católica de São Paulo (PUCSP).

regimeiremaciel@yahoo.com.br

Recebido em 20 de abril de 2011.

Aprovado em 21 de dezembro de 2011. 